\title{
The Cultural Border Crossing Index: implications for higher education teachers in the UAE
}

\author{
Peter Hatherley-Greene \\ Formerly Higher Colleges of Technology, UAE
}

\begin{abstract}
Student transitions from secondary to tertiary education have attracted global attention as universities and colleges of higher education seek to improve student retention. Over the course of one academic year, I documented the transitional experiences of first-year male Emirati students at a college of higher education in a rural location of the United Arab Emirates (UAE). In this paper I describe four categories of cultural border crossing experiences - smooth, managed, difficult, and impossible - with easier and smoother crossing experiences associated with close congruency (related to the students' self-perceived attitude and scholastic preparedness as broadly reflected in their competence in their second language, English) between the predominantly Arabic life-world associated with Emirati families and government schooling and the dominant Western/English language culture in institutes of higher education. Additionally, I describe and evaluate students' cultural border crossing experiences with some Foundation program faculty, finding that those teachers who developed a classroom culture based on Kleinfeld's (1975) notion of 'warm demandingness' and caring rapport-building appeared to have the most positive impact upon the students. Implications from this research have the potential to positively impact both the student and faculty classroom experience in the Gulf tertiary classroom, in addition to improving overall student retention rates.
\end{abstract}

\section{Introduction}

The impetus for this research arose from my 16 years of teaching and management experiences in a single, multi-campus federal institution of higher education in the United Arab Emirates (UAE), the Higher Colleges of Technology (HCT), which is

dedicated to the delivery of technical and professional programs of the highest quality to the students, within the context of sincere respect for diverse beliefs and values. (HCT Catalogue, 2010).

Young Emirati high school-leavers aged around 17-19 who do not meet the minimum English language entry requirements for studying in their career program of choice enter their first year in a Foundation program at the Higher Colleges of Technology (HCT) in the UAE where they begin to recover their skill deficits in English, Math, Computing, and Personal Development. These skills are necessary for them to start their career program of choice in Business, Applied Communications, Information Technology, or Engineering. For too many of them arriving directly from high school, the social, emotional, linguistic, cultural, and cognitive experiences in their first year at college are very difficult and foreign, making the transition from high school to higher education an almost impossible feat for some (Hatherley-Greene, 2012a).

The HCT, established in 1988, has resourced a nationwide community of vocational post-secondary colleges with the latest technology, best resourced campuses and some of the most experienced Western-educated faculty from around the world. The investment is staggering - AED 1.2 billion (\$US 326 million) in the academic and research year 2011-2012 (Swan, 2011). Despite a huge investment in public secondary education, only $10 \%$ of Emirati high school leavers meet the minimum English eligibility benchmark (IELTS minimum 5.0) to enter their first year career program without a 1-2 year academic bridge program which draws heavily on the national budget (UAE 
Yearbook, 2010). Furthermore, only 30\% of Emirati students enrolled in federally-funded universities are men (Ridge \& Farah, 2012). In short, the numbers of male Emirati graduates entering the workforce through the federal system of higher education are comparatively low as many fail to pass the Foundation program. This gender gap as illustrated by low higher education enrolment among male secondary school students has been identified previously by a number of both locally-based and international researchers (Abdulla \& Ridge, 2011; Ridge, 2009a, 2009b, 2010; Minnis, 2006; Hatherley-Greene, 2010; Dahl, 2010; Fields, 2011; Daleure, 2011; Hourani \& Diallo, 2011; Ostrowska, 2011).

In light of this phenomenon, I therefore began to investigate the following two questions:

- Why do so many friendly and respectful male Emirati students come to colleges of higher education but not avail themselves of the learning opportunities that await them in one of the most highly resourced post-secondary institutions in the world?

- Why do so many male Emirati students appear to have low levels of intrinsic motivation for studying and learning in higher education?

In answering these key questions, I sought to describe and categorize the students' transitions as they leave their predominantly Arabic cultural life-world associated with Emirati families, community, and government schooling and attempt to enter the Western/English language culture associated with institutes of higher education in the UAE. Students were surveyed and observed, enabling me to use a diverse range of data, both quantitative and qualitative. Additionally I used data from previous research I had conducted a decade earlier in order to provide chronological comparisons of similar study groups.

Faculty were also interviewed and surveyed, which led to a set of emerging questions related to their role in cultural change, the appropriateness of learner-centred instructional methodology, and efficacious classroom management attitudes.

\section{Background}

The traditional Arabian way of life, centred on the tribe and family, remained more or less undisturbed until midway through the 20th Century, when the discovery of massive oil reserves changed everything. A 'cultural tsunami' was unleashed in the 1980's as hundreds of thousands of unskilled and skilled foreign workers arrived to help extract the oil and develop the young country's infrastructure. The immigration of large numbers of workers from Asia, Europe and North America has produced an unforeseen impact upon the cultural identity of the local Emiratis - this is observed especially in the large urban centres of Abu Dhabi and Dubai where modern skyscrapers (including the highest building in the world, Burj Khalifa), Western hotels, night-clubs, and cinemas (showing Western and Hindi movies) co-exist with mosques, Quranic cultural centres, and camel-racing. Despite a robust Emirati birth rate especially in rural areas, by 2012 the population imbalance between the Emiratis and expatriate workers had reached the point where local Emiratis comprised just $11 \%$ of the total UAE population (UAE population at $8.26 \mathrm{~m}$ in 2010, 2011). Considering how far the country has changed in a little over 50 years, it is not surprising that many Emiratis have mixed feelings about the pace of development in their country (Heard-Bey, 2004; Pearson, 2011; Salama, 2010).

\section{Education}

In the recent past, most young Emirati children traditionally attended state-funded primary and secondary schools, staffed primarily by Arab expatriate teachers from Syria, Jordan, Palestine and Egypt (Ridge, 2010). The teaching methodology employed in the schools naturally arose from the Quranic traditions still found throughout the Arab world: an emphasis on rote memorization, learning only to pass the test, and a strict code of behaviour that places the teacher, not the student, 
firmly and often intimidatingly at the centre of the teaching and learning process (World Bank MENA ECD Report, 2009; Ahmed, 2011; Al Subaihi, 2011; Nereim, 2012).

Due to the sluggishness of the government secondary school system to modernize its teaching methods and improve the quality and effectiveness of teachers, over half of Emirati parents in Dubai now prefer to send their children to expensive private schools (Kenaid, 2011). Despite hundreds of workshops conducted by the Ministry of Education (MOE) to improve teaching methods and instructional approaches, little appears to have changed. This may result partly from the lack of mandatory teaching qualifications including a teaching practicum where teachers learn, practise and demonstrate modern techniques of learner-centred education (Ridge, 2010). Arriving from a motivation-sapping and largely uncaring/disinterested secondary school experience (HatherleyGreene, 2012a), too many ill-equipped and ill-prepared young male Emiratis enter the colleges and universities of higher education with a strong sense of dread and an expectation of failure (Hatherley-Greene, 2012b; Ridge \& Farah, 2012).

\section{Student Retention}

North American research student persistence and retention since the mid-1970s has been strongly influenced by the work of Tinto $(1975 ; 1988 ; 1997 ; 2006)$ and, inspired by his work, many other researchers have contributed to this growing body of knowledge (Pascarella \& Terenzini, 1977, 1979, 1980; Andrade, 2006; Anderman et al., 2006). We now know much more about the successful assimilation and integration of young college-age students into Western college life as well as the process and stages by which they gradually come to a decision to leave. Summarizing the research, it is evident that involvement, engagement, and integration are the key success predictors in a student's first year at college.

Involvement matters (Tinto, 1997), and appears to be a result of the student's energy and effort and it matters most in the crucial first year of a new student's life at college. Astin (1984) defines involvement as the "amount of physical and psychological energy a student devotes to his college experience" (p. 528). Tinto found that increased involvement from the student increases persistence and improves learning outcomes (1997).

Engagement has more to do with the college environment providing diverse, relevant, and novel opportunities for students to become involved and participative, for example, by establishing clubs on campus. Finally, integration, or "a sense of belonging" (Tinto, 1997, p. 599) is a shared responsibility between the student and the institution. For a student to become integrated, they must first be willing to do so by adopting the norms and values of the college culture. In turn, the college must transmit and live its own norms and values so they are clearly and unambiguously received and adopted by the new students (1997).

In local student retention studies, Daleure (2011) completed a study of 294 male Emirati students at a HCT college and found that the key persistence factors at college were parental support, students' own dreams of continuing education, and the perceived quality of post-secondary education institutions within the UAE vis-à-vis study opportunities abroad; this supports many of Tinto's findings. Ridge et al. (2013) found that the process of dropping-out from government schools in the UAE is associated with low socio-economic background, poorly educated and/or uninvolved parents, and de-motivating school experiences marked by unsupportive teachers and disruptive peers.

\section{Research context}

This study took place at a male college in a rural location in the UAE, one of the Higher Colleges of Technology charged with providing post-secondary vocational education exclusively for the young Emirati men and women around the country. Established in 1988 in Abu Dhabi and Al Ain with four colleges (separate male and female colleges at each location), the system of colleges has now grown 
to seventeen colleges (HCT Catalogue, 2010). The system currently offers over 19,000 students a range of career programs in Applied Communications, Business, Education, Engineering, Health Sciences, Information Technology, and General Education; almost all HCT programs are delivered in the English language.

The National Admissions and Placement Office (NAPO) co-ordinates all Emirati secondary student applications for the main publicly-funded higher education institutions in the UAE: UAE University, Higher Colleges of Technology, and Zayed University. Since 2007, all Grade 12 students in their final year of secondary school may make multiple attempts at the Common Educational Proficiency Assessment (CEPA), which measures their level of English language and numerical competence (NAPO, 2012). The CEPA English examination consist of three sections: grammar, vocabulary and reading, and writing.

Table 1: HCT Foundations English levels and their associated equivalencies, 2011 (NAPO, 2012).

\begin{tabular}{|l|c|c|c|c|c|}
\hline HCT Foundations & CEPA English & CEPA Writing & CEFR & IELTS Score & Exit Foundations \\
\hline Direct Entry & $180+$ & $5.0+$ & B2 & IELTS 5.0+ & 0 \\
\hline Level 4 & 170 & 4.0 & B1+ & IELTS 4.5 & 1 \\
\hline Level 3 & 160 & 3.0 & B1 & IELTS 4.0 & 2 \\
\hline Level 2 & 150 & 2.0 & A2+ & N/A & 3 \\
\hline Level 1 & 140 & 1.0 & A2 & N/A & 4 \\
\hline Pre-Fdns & $<140$ & $0-1.0$ & A1 - A1+ & N/A & N/A \\
\hline
\end{tabular}

Table 1 illustrates the equivalencies between IELTS (International English Language Testing System), CEPA and the Common European Framework of Reference (CEFR) which seeks to validate competencies across languages in the European Union (CEFR, 2012). CEPA-English is one of the important requirements for admission, as students with a high CEPA-English score (minimum 180) may be eligible to enter career programs directly. If an applicant obtains a CEPA score of less than 180 but greater than 140 (this was raised to 150 in 2012), s/he may be placed in a Foundation program in order to develop the minimum language and numerical proficiency required for successful study at undergraduate level. In 2010, less than 10\% of Emirati applicants to higher education met the basic proficiency level of English level set at a CEPA score of $185^{1}$, permitting them to proceed directly into their first year of their career programs; thus, in that same year, over 90\% were placed into Foundation programs (UAE Yearbook 2010, 2010).

These Foundation programs are provided at all three UAE federally-funded higher educational institutions to enable those students under 180 CEPA to improve their English language competency, English numeracy skills, computing, and personal and professional development skills. During the 2011-2012 academic year, Foundations in HCT was divided into four levels based on the level of English language competency measured by the students' CEPA scores. For the purpose of this research, Levels 1 and 2 were labelled as 'lower levels' (CEFR descriptors A1-A2 'extremely low to low English ability, beginner level') while Levels 3 and 4 were labelled as 'higher levels' (CEFR descriptors B1-B2 'emerging proficiency, intermediate level'). A level 1 student was permitted to take up to four semesters (two years) to reach IELTS 5.0, the minimum level for entry into HCT's undergraduate career programs. 


\section{Cultural definitions}

This research takes place within the realm of culture, described by Giroux as a landscape filled with multiple and heterogeneous borders where different histories, languages, experiences, and voices intermingle amidst diverse relations of power and privilege (2005, p. 145).

Attempting to assist visitors in negotiating journeys within this landscape, various researchers have proffered 'roadmaps' in the form of cultural models and definitions (Hofstede, 2001; Kroeber \& Parsons, 1958; Goodenough, 1976; Aikenhead, 1996; Trompenaars \& Hampden-Turner, 1998). Though many definitions of culture have been proposed, I prefer Michie's (2011) interpretation:

the social environment in which an individual is raised and lives, [including] a range of concepts and beliefs that is accepted by individuals as defining their group identity. (p. 10).

In the pre-oil times prior to the 1950's, the transmission of Arabian Gulf culture (traditions, norms, values, beliefs, and world-view) from one generation to the next was typically passed on within the family, kin and tribal groups: generally, young people of both genders were encouraged to "behave like adults as soon and as well as possible" (Heard-Bey, 2004, p. 154). Feghali (1997) found that the three basic values most commonly mentioned in the literature on Arab cultural communication patterns more broadly include collectivism, hospitality, and honor:

The influence of [these] Bedouin values remains strong, despite the fact that around $90 \%$ of the population in the region presently resides in villages or cities" (p. 352)

Young Arab males have a higher status in the family compared to females and in the home, there was (and still remains) a high tolerance of young people's behaviour in the early years (Heard-Bey, 2004). Parenting styles are often closely associated with those traditional values reflecting Islamic culture: "respect for elders, good manners, good academic outcomes, and self-discipline" (Alsheikh, Parameswaran \& Elhoweris, 2010, p. 8), resulting often in strict and authoritarian parenting to which Arab youth appear to respond positively (Dwairy \& Mustapha, 2006).

In contrast, the new affluence associated with the country's oil-wealth has resulted inadvertently in the creation of a rentier society (Minnis, 2006), a symptom of which is a growing dependence of Emirati parents upon foreign housemaids and (often untrained) nannies in raising the next generation of Emirati children (Al Sumaiti, 2012). 1). In her report, Al Sumaiti found that

94 percent of Emirati families and only 5 percent of expatriate families employ maids and nannies to do housework as well as look after children. (p. 4)

She goes on to list the negative results of this recent social phenomenon, including harm to the child's maternal attachment causing possible behavioural problems (housemaids typically spend between 30-70 hours a week caring for children), erosion of the traditional Arab values usually passed down through parenting (untrained foreign nannies often have minimal Arabic-speaking skills and little awareness of Arab customs and values), and emotional trauma for the young child when the nanny's two-year contractual agreement ends and she returns to her home country.

When discussing the intercultural landscape, it is easy to adopt naïve and essentialist notions of cultural difference, to which the work of cultural researchers such as Hofstede (2001) and Trompenaars \& Hampden-Turner (1998) has sometimes contributed, through the uncritical adoption of their dichotomized cultural dimensions and orientations such as individualism/collectivism (Holliday, 2011). Essentialist positions on human traits such as gender, sexuality, race, ethnicity, etc, assume that these are fixed, while not allowing for variations among individuals or over time (Cupane, 2008). On the other hand, non-essentialist perspectives assume that the characteristics of individuals, groups and communities exist but that these characteristics are not fixed, varying as they do from individual to individual over time and space. Cultural dimensions and orientations may best be seen as cultural spaces within which people's identities are shaped, and which accommodate also 
meeting points, crossing points or borders which individuals may approach or pass beyond into new cultural spaces.

\section{Cultural border crossing}

In Arab culture, nothing symbolizes the image of a border crossing more viscerally than a checkpoint at Ramallah or Gaza, whereas in Western culture, a border crossing might be likened to the Berlin Wall. Henry Giroux's (2005) cultural border-crossing metaphor provides an appropriate framework to study a people and a society that have moved developmentally from subsistence to an industrialknowledge society in less than two generations. Giroux first applied the border crossing metaphor in the early 1990's as he sought to describe the hardships endured by students in North America whose race and culture were different from those of the dominant group. The concept was further refined and updated in his second edition published in 2005, but his description of the metaphor remains true and powerful:

\footnotetext{
... the concept of borders provides a continuing and crucial referent for understanding the co-mingling - sometimes clash - of multiple cultures, languages, literacies, histories, sexualities, and identities. Thinking in terms of borders allows one to critically engage the struggle over those territories, spaces, and contact zones where power operates to either expand or to shrink the distance and connectedness among individuals, groups, and places. (Giroux, 2005, p. 2)
}

Aikenhead (1996) used Giroux's metaphor to describe the cultural journey experienced by young Canadian science students as they crossed from their known sub-cultures of peer groups and family into the sub-cultural world of science education with its own language, norms and customs, beliefs, world-views and group-think. His view is that students' understanding and learning is perceived as a cultural event - students do not learn in isolation from the cultural elements that make up the learning experience. These elements include the norms, customs, attitudes and values, beliefs, expectations, world-view and conventional actions of a group (Phelan et al., cited in Aikenhead, 1996, p. 7). Similarly, Mulholland \& Wallace (2003) described the border crossings of teacher trainees' "lived experiences of learning to teach" at an Australian university into the sub-culture of the often harsh reality-check of a teacher's first year teaching (p. 882). We can extend Giroux's metaphor of the cultural borders and their crossing by conceptualizing individuals as travellers crossing cultural borders, the ease of which is largely determined by the congruence between individuals' pre-formed world-views and the cultural space into which they are crossing.

\section{Border crossing experiences}

The difficulties experienced during cultural border crossings may be conceptualized as 'hazards' and the degree of difficulty with which a border crossing into a cultural space is achieved may be categorized as smooth, managed, hazardous or virtually impossible (Cobern \& Aikenhead, 1998). The ease of crossing a cultural border is dependent upon the congruence between the world-view of the border crosser and that prevalent in the 'borderlands' - the area between the familiar 'safe zones', where the perspective/culture of the border crosser and that of the new landscape they are approaching begin to interact, dove-tail, mix and blend (see Figure 1).

A student's world-view enables him or her to "gauge the plausibility of any assertion" (Cobern as cited in Aikenhead, 1996, p. 4) or as Aikenhead nicely summarizes, "world-views are culturally validated presuppositions about the natural world" (Aikenhead, 1996, p. 4). Border crossings need not be problematic, as most adults change their behaviours in quite subtle ways as they move from one social context to another. The unifying lubricant that smoothes and facilitates these border crossing experiences is a common culture, particularly exemplified in the form of language: Giroux suggests that

how we understand and come to know ourselves cannot be separated from how we are represented and how we imagine ourselves. (cited in Pillsbury \& Shields, 1999, p. 2) 


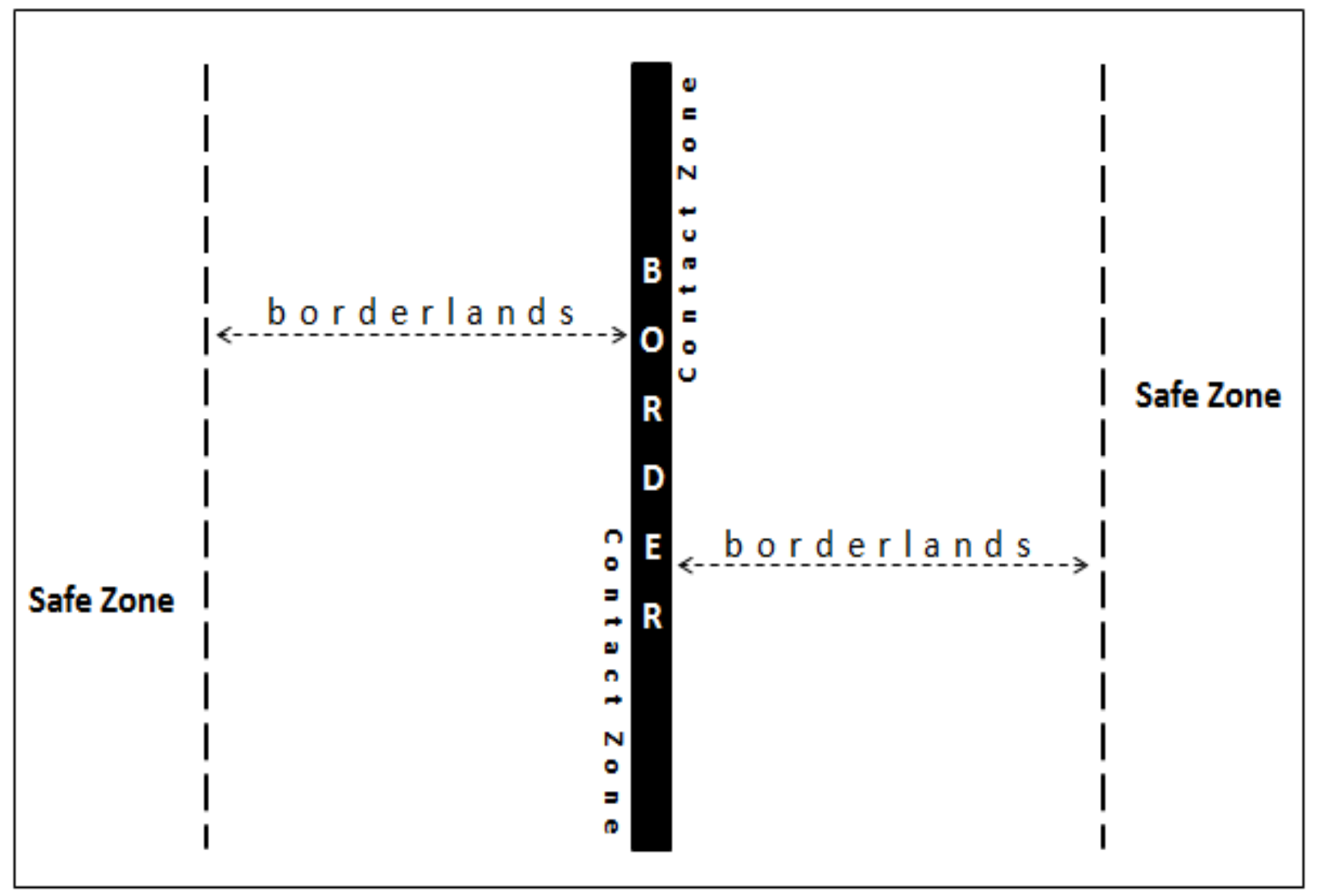

Figure 1: Conceptual model of the border crossing area including zones and barriers.

In Phelan et al.'s (1991) study, students with different cultural identities and 'ways of knowing' to those of Western science encounter obstacles to learning, engagement, and ultimately, enculturation. These learners typically reported border crossing experiences ranging from smooth to impossible. In their research, which was later expanded by Costa (1995), students' border crossing experiences were categorized into four transition experiences based upon the congruency between their world-views and those of science (see Table 2). Students with world-views similar or congruent to that of the new cultural landscape in which they found themselves experienced smooth transitions; students whose world-views were different were able to manage their transitions though the degree of relative difficulty and ease varied; students whose world-views were diverse (beyond 'different' and bordering on 'difficult') experienced hazardous/difficult transitions, with the result that several did not successfully (safely?) negotiate the crossing, and finally, those students with highly discordant world- views increased their resistance to transitions to such a degree that they found it impossible to transition at all (Phelan et al., 1991). As Hennessy (1993) puts it, "crossing over from one domain of meaning to another is exceedingly hard" (p. 9).

Table 2: Movements between different worlds result in different types of crossing (adapted from Costa, 1995; Phelan et al., 1991).

\begin{tabular}{|c|c|}
\hline Movement between... & Type of crossing \\
\hline Congruent worlds & Smooth transitions \\
\hline Different worlds & Managed boundary crossings \\
\hline Diverse worlds & Difficult boundary crossings \\
\hline Highly discordant worlds & Impossible boundary crossings \\
\hline
\end{tabular}

Hatherley-Greene, P.J. (2014). The Cultural Border Crossing Index: implications for higher education teachers in the UAE. Learning and Teaching in Higher Education: Gulf Perspectives, 11(2). http://Ithe.zu.ac.ae 
As established by Costa (1995), Aikenhead (1996), and Driver, Asoko, Leach, Mortimer and Scott (1994), learning is a cultural experience of acquisition, driven by the need for students to acquire a "new community of discourse, a new culture" (Driver at al., 1994, p. 11), not just in the area of science learning but in any area or context where the cultures of the students and the teacher differ. Cultural acquisition is a process of transmission (consciously or unconsciously) of ideas, knowledge and values from one group to another (Hawkins \& Pea, 1987). This process can be supportive or disruptive according to whether the student's world-view is similar or different to that of the 'transmitting culture' (Baker \& Taylor, 1995). If the transmitting (new) culture is congruent or harmonizes with the student's world-view, the new culture will support the student's world-view as a result of enculturation - if the transmitting (new) culture is incongruent or is at odds with the student's world-view, the new culture may disrupt the student's world-view to such an extent that they replace their own culture with the new culture: a result of assimilation.

\section{Methodology}

The research involved tracking over one academic year (2011-2012) a sample of 60 new Foundations students, who had been placed in four levels in the college (see Table 3 ) based on their English language competence as measured by the Common Educational Proficiency Assessment (CEPA). Almost 190 new students were registered and confirmed on the first day of the semester. However, due to high no-show and attrition rates, only 60 students completed the surveys several weeks into their first semester and then continued into the second semester.

Table 3: Foundations student population by level, status and CEPA range, 4 September 2011.

\begin{tabular}{|l|c|c|c|c|c|c|}
\hline Level & $\begin{array}{c}\text { Returning/ } \\
\text { Promoted }\end{array}$ & $\begin{array}{c}\text { Returning/ } \\
\text { Repeating }\end{array}$ & New & $\begin{array}{c}\text { Student } \\
\text { Survey }\end{array}$ & $\begin{array}{c}\text { CEPA Placement } \\
\text { Range for new } \\
\text { students }\end{array}$ & Total \\
\hline Level 1 & N/A & 0 & 61 & 19 & $140-149$ & $\mathbf{6 1}$ \\
\hline Level 2 & 13 & 11 & 70 & 18 & $150-159$ & $\mathbf{9 4}$ \\
\hline Level 3 & 10 & 5 & 40 & 23 & $160-169$ & $\mathbf{5 5}$ \\
\hline Level 4 & 38 & 5 & 18 & 0 & $170-179$ & $\mathbf{6 1}$ \\
\hline Total & $\mathbf{6 1}$ & $\mathbf{2 1}$ & $\mathbf{1 8 9}$ & $\mathbf{6 0}$ & & $\mathbf{2 7 1}$ \\
\hline
\end{tabular}

My approach can be compared to that of a bricoleur or 'quilt-maker', implying that each patch of cloth with its unique dimensions of different colours and textures contributes to the overall shape of the completed quilt. At various times, those patches of quilt were formed by adopting a postpositivist stance, enabling me to describe and explain general social patterns of behaviour through surveys based on the quality standards of researcher objectivity, construct/predictive/internal validity, generalisability, reliability, and triangulation. At other times, I created different patches from an interpretivist stance which facilitated an open, artful, and interpretive exploration of complexity through observation, case studies, interviews, focus groups, journals and student narratives based on the quality standards of immersion within the setting, member checking, listening and recording participants' voices, making tentative and cautious claims, and respecting the process of understanding through emergence. The postmodernist patches remind us all at this point in the 21st Century to disrupt the presumed primacy of any paradigm by embracing difference, tension, and pluralism. Finally, I sought to uncover hitherto hidden and unequal relationships by adopting a critical stance that seeks to help those without power to acquire it (Willis, 2007), based 
upon the quality standards of critical self-reflection and self-study, and displaying and 'living' ethics of care, fairness, and empowerment.

\section{Border crossing index $(\mathrm{BCl})$}

Four categories of student border crossers were proposed - smooth, managed, difficult, and impossible - and a Border Crossing Index (BCl) was constructed from an analysis of student responses in a 50-item Student Survey. Translated into Arabic, the survey was adapted from the Patterns of Adaptive Learning Scales (PALS) which were developed by a US-based group of researchers led initially by Carol Midgley, who used goal orientation theory to examine the relation between the learning environment and students' motivation, affect, and behaviour (Midgley et al., 1998). The student scales assessed student perception of the transition from high school to college, the motivation to learn, self-evaluation of persistence in learning, learner-centred teaching practices, and a self-assessment of their home lives including perceptions of their parents, high school experiences, and abilities. For example, question 21 under the section Motivation to learn reads: "When I find I can't complete a task, I tend to give up and ask my friends for help." Students are then asked to circle one of the Likert scale numbers from 1 to 5 (Not at all true to Somewhat true to Very true). The details of the methodology and process in creating the Border Crossing Index may be read in previously-published papers and book (HatherleyGreene, 2012a; Hatherley-Greene, 2014). The survey was administered in the first few weeks of the first semester.

Based upon each individual $\mathrm{BCl}$ score, 60 first-year male students were placed into the four broad categories (see Table 4). Nearly a quarter of the students fell into each of the 'difficult' or 'smooth' categories, as might be expected if students were placed in a category at random (25\%). The category 'managed' comprised over half the new students (52\%) while the final 'impossible' category contained only one student who left within the first 20 days of the semester.

Table 4: Proportion of students in each border crossing category.

\begin{tabular}{|l|c|c|c|c|}
\hline $\begin{array}{l}\text { Border Crossing } \\
\text { Category }\end{array}$ & $\begin{array}{c}\text { BCl Class } \\
\text { Interval ranges }\end{array}$ & $\begin{array}{c}\text { Frequency } \\
\mathbf{n = 6 0}\end{array}$ & $\begin{array}{c}\text { Predicted } \\
\text { Proportions }\end{array}$ & $\begin{array}{c}\text { Actual } \\
\text { Proportion }\end{array}$ \\
\hline Smooth & $40-33$ & 14 & $25 \%$ & $23 \%$ \\
\hline Managed & $32-24$ & 31 & $25 \%$ & $52 \%$ \\
\hline Difficult & $23-16$ & 14 & $25 \%$ & $23 \%$ \\
\hline Impossible & $15-8$ & 1 & $25 \%$ & $2 \%$ \\
\hline
\end{tabular}

The apparent difficulty and incongruence of the cultural border crossing experiences is highlighted by the fact that $72 \%$ of the 60 students reported in later focus group meetings (see below) that they were generally "confused and lonely" in their first week of college and $84 \%$ felt generally "troubled" because their home and college lives were so different - seven of the 13 Level 2 students who took part in the student focus group in March 2012 reported that they felt they were "entering a strange new world".

This state of "normlessness" (Tinto, 1988, p.442) is best illustrated by reviewing the enrolment numbers by program level over the duration of the critical first semester (see Figure 2). Level 1 and 2 students 'talked with their feet', withdrawing in substantial numbers from college over this period. In comparison, the higher level students remained in college, successfully moving up a level at the end of the semester. Difficult cultural border crossings associated with lower level students also meant they were more likely to disrupt classroom lessons: $27.5 \%$ of lower level students compared to $15.5 \%$ of higher level students reported that they sometimes disturb the lesson when they get 
bored or cannot do the work. The lower level students also left college earlier to take up full-time employment (42.5\% of lower level students compared to $18.5 \%$ of higher level students withdrew from college during Semester 1). $62 \%$ of the total withdrawn students who eventually went on to leave by the end of the first semester had withdrawn by Day $20.68 \%$ of all the students who officially withdrew during Semester 1 notified college that they were withdrawing for employment reasons.

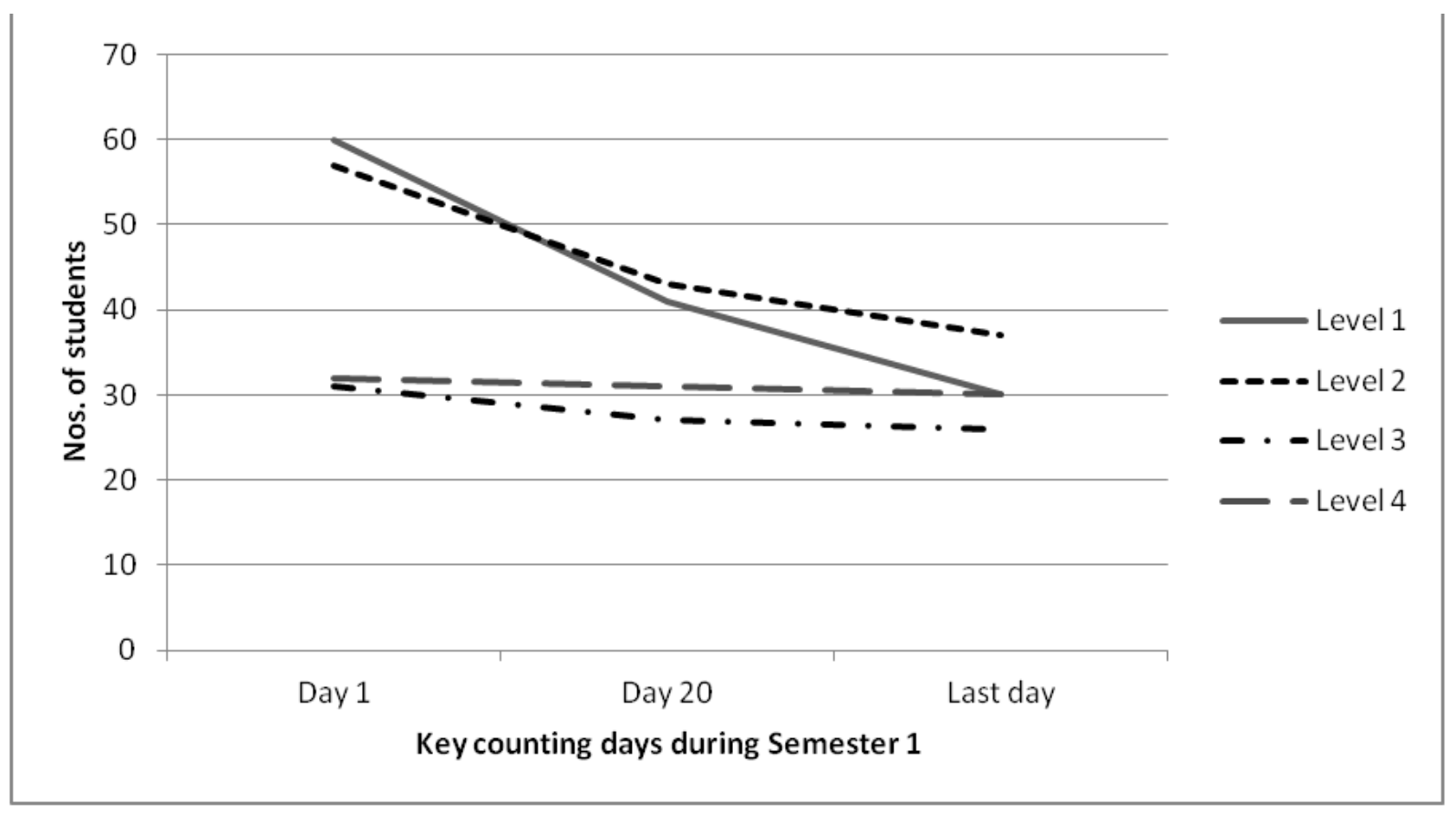

Figure 2: Enrolment by level (Foundation, semester 1, 2011-2012).

At the end of the academic year in June 2012, I reviewed the original BCl profiles for the 60 students who remained and I found that the composition of the remaining cohort had changed dramatically over the year (see Figure 3). By the end of the academic year in June 2012, there were no students remaining in the program categorized as 'impossible', and the 'difficult' category proportion had decreased from $23 \%$ to $10 \%$. The 'smooth' category increased its percentage proportion from $23 \%$ to $35 \%$, highlighting the apparent cultural congruency and ease of their border crossing experience. Overall, the $\mathrm{BCl}$ appeared to indicate that students categorized in the 'difficult' to 'impossible' categories experienced sufficient cultural and learning discomfort to hasten their withdrawal from college in order to take advantage of attractive high starting salaries in government organizations in the Abu Dhabi emirate (particularly as employment incentives in the period following the Arab Spring).

\section{Border crossing grounded models}

In two separate focus group meetings with students and HCT teachers, we explored together their border crossing experiences, the result of which was the creation of two models that sought to capture the geography, movement, and politics of cultural border crossings in the UAE. The Student Cultural Border Crossing Model is described in earlier papers (Hatherley-Greene, 2012a; HatherleyGreene, 2012b; Hatherley-Greene, 2013). 


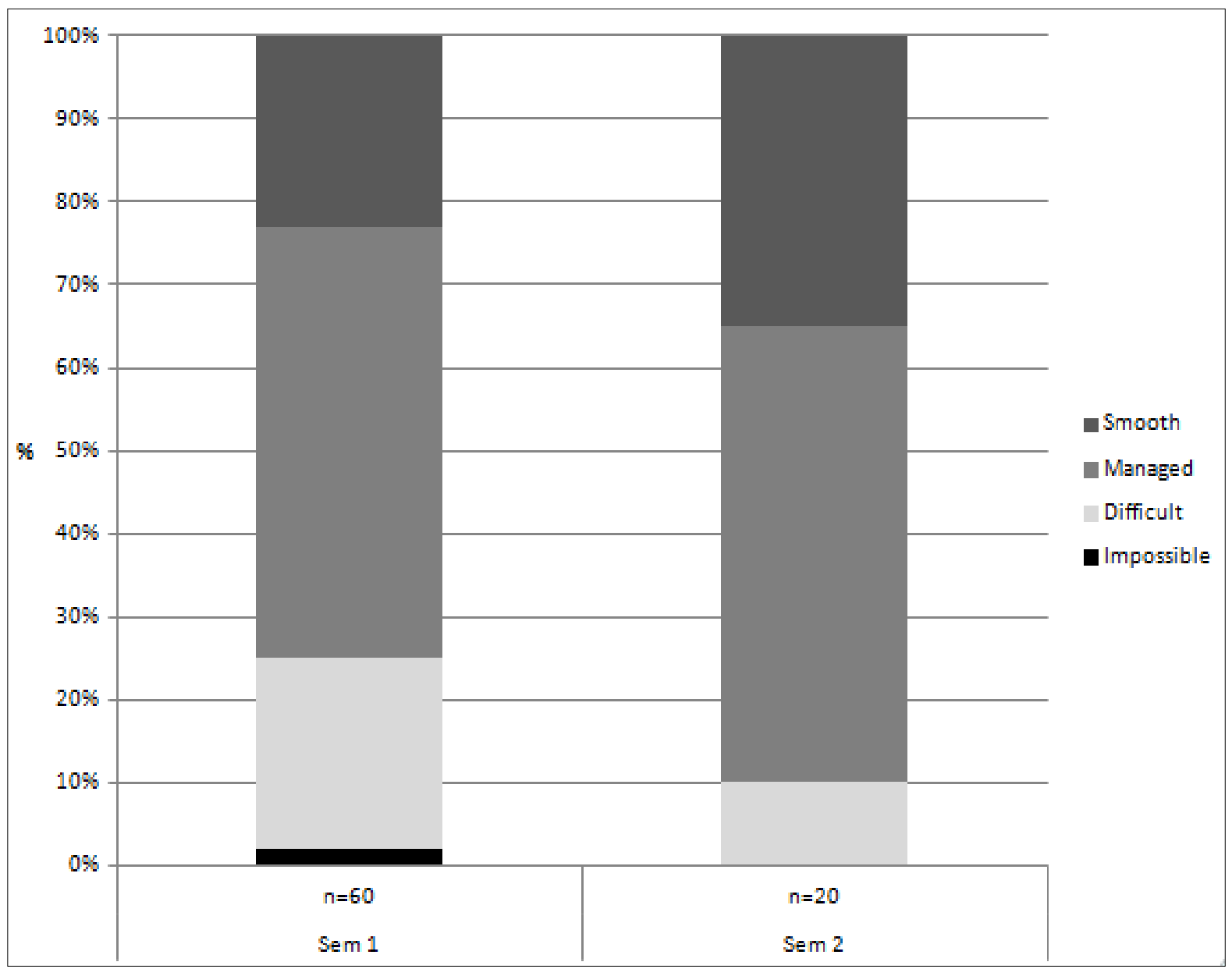

Figure 3: Proportions of students by Border Crossing Index (new students survey sample, 2011-12).

\section{A cultural border crossing model for faculty}

Like the students, faculty start within their Safe Zone (see Figure 4) - for some, this means their 'home countries'; for others it may simply be the homes in Fujairah which they share with husbands, wives and children. Usually another Safe Zone for many teachers during the academic year is their faculty workstation, college cafeteria, gym or faculty lounge (a). Safe Zones do not have space for students unless it is at the invitation of the faculty themselves. During the college day, faculty leave their Safe Zone and approach the Contact Zone where they meet and interact with Arab Emirati students in the scheduled lessons (b). Most faculty do this with well-prepared, student-focused interactive lessons filled with innovative applications using educational technology. Their lessons are delivered largely undisturbed by student misbehavior, though strong classroom and lesson management strategies ensure that students are kept busy with bite-sized, task-oriented activities. Many faculty enjoy the borderland experience with minimal discomfort - but for others, the daily border crossing experiences are stressful, resulting in fatigue, poor learning outcomes for the students, and often a one-time only employment contract for three years (c).

Faculty who enjoy the cultural and educational interaction with their students may tentatively cross the border into the students' borderlands and return (d). This may happen during a lesson which is framed with an Arab flavour or on a day fieldtrip with the students on a bus. Finally, for some faculty who regularly cross the border, the cultural barrier appears to disappear and they remain with their students, moving back and forth seamlessly between the two borderlands (e). Giroux (2005) highlights this final scenario when he states that 
teachers become border-crossers through their ability to not only make different narratives available to themselves and other students but also by legitimating difference [my emphasis] as a basic condition for understanding the limits of one's own voice" (p. 146).

By this, I mean that teachers can live within both borderlands, where different perspectives and identities co-exist as part of a pedagogical practice that seeks to expand their cultural horizons.

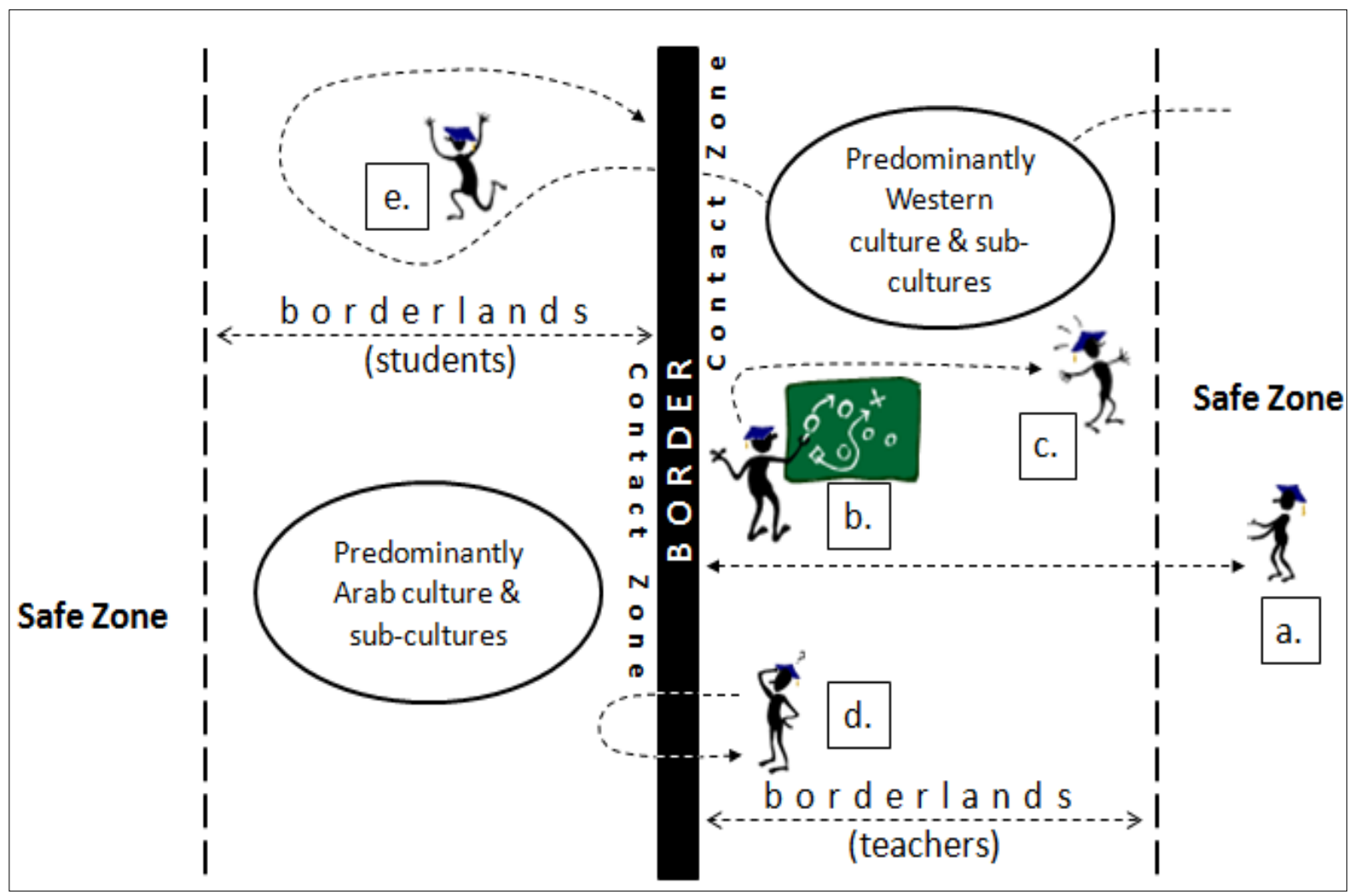

Figure 4: Model of the faculty border crossing experience at Fujairah Men's College.

\section{Faculty teaching approach typologies}

Ten English language teachers were involved at some time during the academic year in directly teaching the study cohort of 94 Level 2 students who were enrolled in September 2011. Of the ten teachers, seven were formally interviewed and transcripts made while well over half were present both times at the two faculty focus meetings (March and April, 2012). One teacher left HCT at the end of Semester 1 in January 2012.

The cultural border crossing model made sense to the Foundations faculty as it appeared to accurately capture the entire gamut of their contact zone experiences. By and large, those experiences with male Emirati students were mostly positive, with the more traditional faculty (identified as those who have taught in the region for over 10 years with a preference for retaining formal, professional relationships with their students) reporting mixed to negative experiences. Almost all faculty recognized value system differences between themselves and the students, and most were aware of some type of cultural boundary. Traditional faculty confirmed they were border crossers (elements ' $d$ ' and ' $e$ ' in the model) along with the others yet they also felt the need to maintain a distance between themselves and the students. Half the faculty considered a cultural change agent role as inappropriate, even "dangerous", though all recognized that simply being in class as a Westerner teaching a foreign language resulted in an unconscious role of exposing their Arab learners to different values and world-views. 
The PALS Teacher Survey (Midgley et al., 1998) was administered to nine current or past Level 2 Foundations teachers to assess the teachers' perceptions of the mastery and performance goal structure for students, approaches to instruction, and their personal teaching efficacy. This survey is based upon Goal Orientation theory which examines the reasons why students engage in their academic work. The theory has two classes of goals - mastery and performance goals (Pintrich, 2000).

Foundations faculty had a strong focus on mastery goals (learners wish to truly understand or master the lesson or skill being taught) in terms of their teaching expectations but there was a disconnect between this mission and strategies, and their ratings of personal teaching efficacy - this was typically manifested through comments in the first faculty focus meeting in March 2012 . $80 \%$ of them agreed with the PALS survey statement 'Factors beyond my control have a greater influence on my students' achievement than I do'. When I explored this further, I asked if their apparent frustration (and sense of powerlessness?) with the current modus operandi was caused mainly by $a$ priori or concurrent factors. The faculty reported issues with both a priori and concurrent factors with the former being the low level of student academic preparedness and motivation combined with English level misplacement which results in too many students finding themselves in levels too high for them. Concurrent factors focused mainly on HCT and college policies such as the perception by faculty that the HCT attendance policy had "no teeth", the "messy start" to the academic year with new students being allowed into class as late as week 5, frequent changes to student and faculty schedules, and the relatively late distribution of student laptops. As one faculty commented, "there seems to be a disconnect between what would be ideal [...] and what actually is".

Giroux (2005) reminds us that in terms of critical pedagogy, there is a "need to name the contradiction between what schools claim they do and what they actually do" (p. 125). This contradiction is further reinforced by Price \& Richardson (2004) when describing the difficulty facing higher education teachers who wish to improve student learning and academic outcomes. The lack of time and constant institutional and academic demands result

in increased workloads where the strategy adopted by teachers is often one of doing what is possible as opposed to doing what is desirable. (p.115, emphasis in original).

This was a sentiment clearly shared by many of the faculty who responded.

\section{'Warm demandingness'}

Judith Kleinfeld's (1975) exploration of the attitudes and characteristics of teachers working with indigenous students in North America highlighted two main traits that distinguish an effective teacher from an ineffective one: "the effective teacher's ability to create a climate of emotional warmth" (p. 318) and "after personal rapport had been established, they [effective teachers] demand a high level of academic work" (p. 326). In the second faculty focus group meeting, faculty were shown the typology below and then asked to declare which type best described them (see Figure 5). Two-thirds of the faculty declared for 'warm demandingness'. Two different sources of support give these declarations some import.

Firstly, the students themselves reported strongly in favour of teachers who set tasks slightly above the students' ability, who do not let the students do just easy work but make them think, and who ensure the students understand the ideas, not just memorize them (Hatherley-Greene, 2012a). Second, further support comes from a local study of parenting styles in Dubai which found that parental demandingness has a significant impact on GPA scores (Alsheikh et al., 2010). Carol Midgley's group at the University of Michigan additionally provided support for 'warm demandingness' when they highlighted the

importance of creating a classroom environment in which students experience both high academic expectations and a supportive student-teacher relationship. (Marachi et al., 2001, p. 12). 
In several conversations with experienced English faculty around the HCT system during the research period, it is evident that 'warm demandingness' is a trait that works very well with Foundation students.

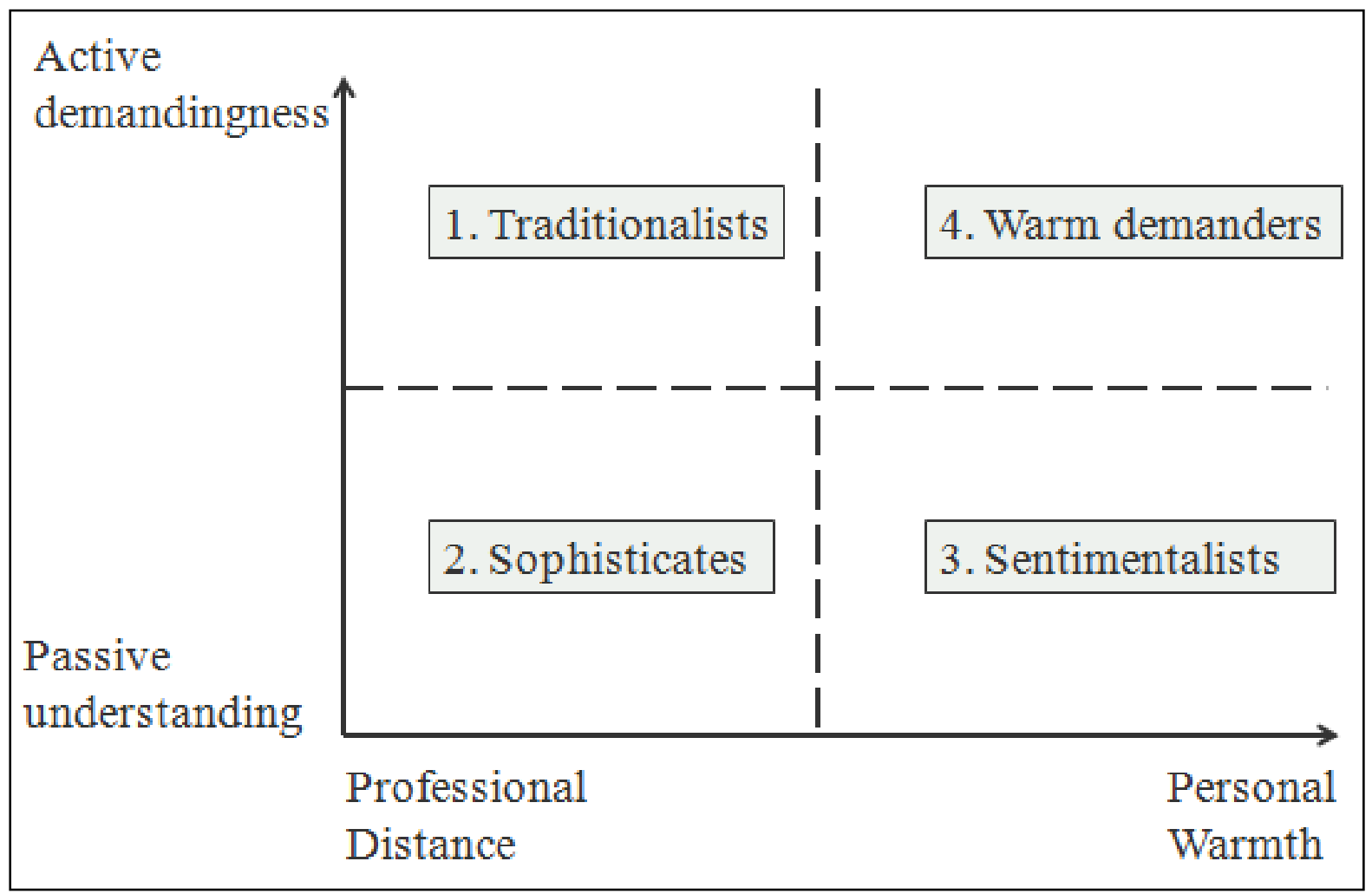

Figure 5: Typology of teaching approaches (Kleinfeld, 1975, p. 329),

I wanted to explore the relationship between the teacher's self-declaration based on Kleinfeld's typology, my assessment of their typology (based on lesson observations and comments in faculty focus meetings, the Teacher Survey, and formal interviews) and the perception students have of them as measured by the student-faculty evaluations. Out of ten faculty, eight gave me permission to view their recent student-faculty evaluations. I selected nine items from the 18-item studentfaculty evaluation instrument as representative of actions or indications associated with faculty's efforts to establish rapport, as opposed to others that focused more on instructional strategies. A mean rapport score was calculated from their individual course evaluations in Semester 1.

The comparison between the self-declared typology, my assessment of their typology, and the rapport score may be viewed in Table 5 . Overall, it is seems that the faculty members whose teaching approach was declared (and corroborated by me) as a Warm Demander obtained the highest rapport scores. Reviewing the student comments from the Warm Demanders' evaluations, students appreciate attempts at humour (but always with the important corollary of effective class management strategies to control the students and bring them back on-task), they like when teachers are kind ('flexible'?), and they know when teachers are putting effort into creating varied and interesting learning experiences. Faculty who demand but without obvious warmth (traditionalists) scored the lowest rapport scores - their student comments referred to a "lack of smiling" and "serious" facial expressions. Sentimentalists appear to be well liked by the students as they appear to have a more relaxed attitude in general. 
Table 5: Comparison of faculty rapport scores with teaching approaches.

\begin{tabular}{|c|c|c|c|}
\hline $\begin{array}{c}\text { Faculty } \\
\text { member }\end{array}$ & Self-Declaration & My Assessment & Rapport Score \\
\hline A & Warm Demander & Warm Demander & $88 \%$ \\
\hline B & Warm Demander & Warm Demander & $88 \%$ \\
\hline C & Warm Demander & Warm Demander & $88 \%$ \\
\hline D & $\begin{array}{c}\text { Sentimentalist/ } \\
\text { Warm Demander }\end{array}$ & $\begin{array}{c}\text { Sentimentalist/ } \\
\text { Warm Demander }\end{array}$ \\
\hline E & Sophisticate/ Sentimentalist & Sentimentalist & $81 \%$ \\
\hline F & Warm Demander & Warm Demander & $79 \%$ \\
\hline G & $\begin{array}{c}\text { Sophisticate/ } \\
\text { Warm Demander }\end{array}$ & $\begin{array}{c}\text { Traditionalist/ } \\
\text { Warm Demander }\end{array}$ \\
\hline
\end{tabular}

\section{Gentle teasing}

Many faculty were observed in acts of "gentle teasing" (Anderman et al., 2006, p. 989). An example which I observed one day in a classroom observation was a teacher's encouraging and positive remark: "Wow, you're on fire today, Ahmed! Did you have a good sleep last night?" This teasing is a respectful but cheeky behaviour trait associated with 'warm demanders' (an example of rapport building that simply says to the student, "I notice you"). One teacher shared an incident with me which I repeat here as an excellent example of both an ironic metaphor which the students instantly grasped, and additionally an insight into the students' self-perceived roles within the learning process at college:

After a dismal result on an assessment (and a similar result on a practice and revision assessment), I was spurred to ask the boys where they saw themselves in all of this. I drew an airplane on the whiteboard with a landing strip and control tower below it. I told them that the plane landing safely was them passing out of Foundations and achieving their IELTS requirement to attend this college or another university.

I asked them, "Where are you on this plane?"

They answered, "The passengers!"

I said, "Actually you are all the pilots of your own planes, aiming for your own successful landing. I'm not the pilot, and sometimes I think you believe I'm the stewardess!" and I mimed taking drinks to them on a tray at which they screamed with laughter. I continued, "I am actually in the control tower down on the ground, and I'm seriously considering leaving my radar screen and going for a coffee 'cause I'm not sure I can bear to watch what's coming! (Personal communication).

\section{Learner-centredness}

Marilyn Dahl and others have cautioned on the appropriateness of the current instructional approach underpinned by constructivist epistemology (often incorrectly labelled as a 'constructivist teaching approach' or simply 'constructivism') that is largely implemented at the three main higher educational institutions in the UAE (Dahl, 2010; Porcaro, 2011). From the early 1980s, constructivism as a learning and instructional theory has swept aside the 'old ways' of teacher-centric instructivism underpinned by a collage of behaviourist and cognitivist epistemologies and championed by leading theorists such as Skinner and Thorndike (Porcaro, 2011, p. 42). However, several researchers have cautioned against this almost slavish adherence to constructivist-based teaching practices, especially in non-Western cultures where students' fundamental exposure in their early learning to more 
traditional teaching and learning pedagogies based on an objectivist epistemology may lead to a loss of teaching effectiveness, low motivation, and cultural hegemony (Dahl, 2010; Hatherley-Greene, 2010; Spector, 2001). Additionally, there continue to be calls for an acceptance of greater 'pluralism' in teaching pedagogies underpinned by the antithetical epistemologies of objectivism and constructivism (Willison \& Taylor, 2006).

Instructional methodologies closely allied to instructivist teacher-centrism, such as rote memorization, have received much vilification over the years. On the other hand, strong support for targeted memorization has come recently from Scott Thornbury and Zoltan Dörnyei among others (Dörnyei, as cited in Thornbury, 2011) in recognition that learning a foreign language "seems to require possession of unusual memory abilities, particularly the retention of verbal material" (Skehan, as cited in Thornbury, 2011). It is not surprising that the highest level of withdrawal rates occurred among the lowest levels in Foundations, indicating a level of learner discomfort observed and confirmed by faculty themselves in the second faculty focus meeting. I found that most lower level students needed at least a year to adapt to learner-centred teaching methodologies, reflecting their lower levels of academic preparedness, Western enculturation, and second language competence; but also many students told me that they eventually "get used" to college including the different way of learning.

In summary, traditional faculty who prefer to keep a professional distance between themselves and the students, and who appear to be reluctant 'border crossers' generally fail to establish rapport with their students as indicated by the student-faculty evaluations and my own classroom observations. Building rapport is an important part of the social integration of students into college life - students who are already pre-disposed to leaving college may quickly reach their individual 'tipping points' due to failure to bond with their peer group, their teachers, and the college. I would encourage all teachers at institutes of higher education in the UAE to adopt the following mantra as they walk towards their first lesson of each day: Build rapport before asking for more. Adjusting teaching styles to greater teacher guidance with an emphasis on structured lessons and bite-sized tasks with plenty of scaffolding in the early weeks of the first semester will assist many lower level students to more easily 'bridge the gap' by affording them a learning experience with which they are already familiar.

\section{Suggestions}

My research produced 54 suggestions for change, ranging from a macro societal view of the country as a whole to a micro pedagogical view of the classroom. I now offer this selection, focused on improving the quality of the learning experience in colleges and universities of higher education in the UAE:

1. Organize student orientation programs to smooth students' entry.

2. Adopt a teacher-centric approach early in the first weeks of contact and gradually, slowly, shift towards greater learner independence.

3. Build a sense of space and belonging by assigning home rooms.

4. Encourage faculty to spend time at the beginning of a new course to build rapport with their students by showing care and empathy, respect for their culture, and interest in the students' lives outside of the classroom.

5. Then, and only after rapport has been established, focus on setting and maintaining high standards of classroom behaviour, academic progress, and sense of achievement.

6. Begin each class with an attention-grabber or bridge-in to engage students, for example, "Does anyone want to share what they did on the weekend?" or show a video from YouTube which is controversial (in a locally appropriate sense) or newsworthy. 
7. Encourage learner input into short-term weekly lesson planning in terms of what is to be learned, when, how and why (relevancy).

8. Ask questions, rather than telling: be very careful to elicit contributions from students and keep 'teacher talking time' in check.

9. Students have different learning preferences: use a learning styles instrument such as VARK (2011) to raise awareness of these preferences.

10. Use the students' lives, prior learning, and their culture as the context for much of their early learning.

11. Give students opportunities to apply their new knowledge in diverse and open-ended projects (be creative in assigning marks in group projects, e.g. give them a $100 \%$ and ask them to assign it to individuals based on their level of contribution).

12. As students may well have experienced being punished for making mistakes, show them that mistakes are great learning opportunities which may contribute to meaningful learning

13. Use low-stakes formative assessments more than single higher-stakes summative assessments.

\section{Epilogue}

Of the 116 new Foundations students who physically arrived at the college door on Day 1 for the start of the first semester on 4 September 2011, only 39 students remained on the last day of Semester 2 on 7 June 2012, including the seven students who progressed successfully into their career programs. The lowest level students have a very poor chance of making it through their first year of higher education. Therefore, a key emerging question is: whose interests are being served (or not) by expecting students to cross sometimes stressful cultural borders into college life with insufficient support, and asking them to study using the dominant second-language of English?

\section{References}

Abdulla, F, \& Ridge, N. (2011). Where are all the men? Gender, participation and higher education in the United Arab Emirates. Dubai School of Government, Working Paper No.11-03. Retrieved from http://www.dsg.ae/en/Publication/Pdf_En/WP11-03.pdf

Ahmed, A. (2011, January 9). Corporal punishment still rife in schools. The National. Retrieved from http://www.thenational.ae/news/uae-news/education/corporal-punishment-still-rife-in-schools

Aikenhead, G. S. (1996). Science education: border crossing into the subculture of science. Studies in Science Education, 27, 1-52.

Alsheikh, N., Parameswaran, G., \& Elhoweris, H. (2010). Parenting style, self-esteem and student performance in the United Arab Emirates. Current Issues in Education, 13(1), 1-26.

Al Subaihi, T. (2011, June 21). A necessary evil in education, whose days are numbered. The National. Retrieved from http://www.thenational.ae/thenationalconversation/comment/a-necessary-evilin-education-whose-days-are-numbered

Al Sumaiti, R. (2012). Parental involvement in the education of their children in Dubai. Policy Brief No.30, Dubai School of Government. Retrieved from http://www.dsg.ae/en/Publication/Description.aspx?PublD=293

Anderman, L., Andrzejewski, C. E., \& Allen, J. (2006). How do teachers support students' motivation and learning in their classrooms? Teachers College Record, 113(5), 969-1003.

Andrade, M. S. (2006). International student persistence: integration or cultural integrity? Journal of College Student Retention, 8(1), 57-81. 
Astin, A. W. (1984). Student involvement: a developmental theory for higher education. Journal of College Student Development, 40(5), 587-599.

Baker, D., \& Taylor, P. C. S. (1995). The effect of culture on the learning of science in non-western countries: The results of an integrated research review. International Journal of Science Education, 17(6), 695-704.

CEFR. (2012). Common European Framework of Reference for Languages: Learning, Teaching, Assessment. Retrieved from http://www.coe.int/t/dg4/linguistic/cadre1_en.asp

Cobern, W. W., \& Aikenhead, G. S. (1998). Cultural aspects of learning science. In B. J. Fraser and K. G. Tobin (Eds.), International handbook of science education. Dortrecht, Netherlands: Kluwer Academic Publishers. (39-52).

Costa, V. B. (1995). When science is "another world": Relationships between worlds of family, friends, school, and science. Science Education, 79(3), 313-333.

Cupane, A.F. (2008). Towards a culture-sensitive pedagogy of physics teacher education in Mozambique. Doctoral dissertation. Curtin University of Technology, Bentley, W.A. Retrieved from http://espace.library.curtin.edu.au

Dahl, M. (2010). Failure to thrive in constructivism - a cross-cultural malady. Transgressions Cultural Studies and Education, Vol. 62. Rotterdam: Sense Publishers.

Daleure, G. (2011). Factors affecting persistence in post-secondary education: a case study of Emirati males. In C. Gitsaki (Ed .), Teaching and Learning in the Arab World (pp. 49-70). Bern, Switzerland: Peter Lang.

Driver, R., Asoko, H., Leach, J., Mortimer, E., \& Scott, P. (1994). Constructing scientific knowledge in the classroom. Educational Researcher, 23(7), 5-12.

Dwairy, M., \& Mustapha, A, R. (2006). Parenting styles in Arab societies: A first cross-regional research study. Journal of Cross-Cultural Psychology, 37(3), 230-247.

Feghali, E. (1997). Arab cultural communication patterns. Journal of Intercultural Relations, 21(3), 345-378.

Fields, M. (2011). Learner motivation and strategy use among university students in the United Arab Emirates. In C. Gitsaki (Ed.), Teaching and Learning in the Arab World (pp. 29-48). Bern, Switzerland: Peter Lang.

Giroux, H. (2005). Border crossings: cultural workers and the politics of education (2nd ed.). New York: Routledge.

Goodenough, W. H. (1976). Multiculturalism as the normal human experience. Anthropology \& Education Quarterly, 7(4), 4-7.

Hatherley-Greene, P.J (2010). Cultural border crossings - transiting from school to college. Paper presentation at TESOL Arabia Conference, Dubai, United Arab Emirates.

Hatherley-Greene, P.J. (2012a). Cultural border crossings: Improving transitions from high school to higher education. Doctoral dissertation. Curtin University of Technology, Bentley, W.A., Australia.

Hatherley-Greene, P.J. (2012b). Cultural border crossings in the UAE. Policy Paper No.6, Al Qasimi Foundation for Policy Research. Retrieved from http://www.alqasimifoundation.com/Libraries/Publications/Pub8paper_Peter_Hatherley_Greene.sflb.ashx

Hatherley-Greene, P.J. (2013). Cultural Border Crossings in the UAE. In D. Fisher, R. Koul \& A. Shuailai (Eds.), Transformations through science, Mathematics and Technology Education: Towards an 
innovative and sustainable society. (pp. 83-89). Proceedings of the Seventh International Conference on Science Mathematics and Technology Education. Perth: Curtin University.

Hatherley-Greene, P.J. (2014). Cultural border crossings in the UAE: Improving transitions from high school to higher education. Saarbrücken: Lambert.

Hawkins, J., \& Pea, R. D. (1987). Tools for bridging the cultures of everyday and scientific thinking. Journal of Research in Science Teaching, 24(4), 291-307.

HCT Catalogue 2010-2011. (2010). Abu Dhabi, UAE: Higher Colleges of Technology.

Heard-Bey, F. (2004). From Trucial States to United Arab Emirates. Dubai: Motivate Publishing.

Hennessey, S. (1993). Situated cognition and cognitive apprenticeship: Implications for classroom learning. Studies in Science Education, 22, 1-41.

Hofstede, G. (2001). Culture's consequences: comparing values, behaviours, institutions and organizations across nations (2nd. ed.). London: Sage Publications.

Holliday, A. (2011) Intercultural Communication and Ideology. London: Sage

Hourani, R. B., \& Diallo, I. (2011). Teaching in the Arabian Gulf: Arguments for the deconstruction of the current educational model. In C. Gitsaki (Ed.), Teaching and Learning in the Arab World (pp. 335-355). Bern, Switzerland: Peter Lang.

Kenaid, K.S. (2011). In search of good education: why Emirati parents choose private schools in Dubai. Retrieved from http://www.khda.gov.ae/CMS/WebParts/TextEditor/Documents/InSearchofGoodEducation_Eng. pdf

Kleinfeld, J. (1975). Effective Teachers of Eskimo and Indian Students. The School Review, 83(2), 301344.

Kroeber, A. L., \& Parsons, T. (1958). The concepts of culture and of social system. American Sociological Review, 23, 582-583.

Marachi, R., Friedel J., \& Midgley, C. (2001). I sometimes annoy my teacher during math: relations between student perceptions of the teacher and disruptive behavior in the classroom. Paper presented at the annual meeting of the American Educational Research Association, Seattle, WA, 11-16 April 2001.

Michie, M. G. (2011). Working across cultures in indigenous science education. (Doctoral dissertation). The University of Waikato, Hamilton, New Zealand.

Midgley, C., Kaplan, A., Middleton, M., Urdan, T., Maehr, M. L., Hicks, L., Anderman, E., \& Roeser, R. W. (1998). Development and validation of scales assessing students' achievement goal orientations. Contemporary Educational Psychology, 23(2), 113-131.

Minnis, J, R. (2006). First nationals education and rentier economics: parallels with the Gulf states. Canadian Journal of Education, 29(4), 975-997.

Mulholland, J., \& Wallace, J. (2003). Crossing borders: learning and teaching primary science in the pre-service to in-service transition. International Journal of Science Education, 25 (7), 879-898.

NAPO. (2012). CEPA. Retrieved from http://ws2.mohesr.ae/NAPO/Details_EN.aspx?str=CEPA

Nereim, V. (2012, April 29). School violence: the truth behind a tragedy. The National. Retrieved from http://www.thenational.ae/news/uae-news/education/school-violence-the-truth-behind-atragedy 
Ostrowska, S. (2011). The effect of course content on student motivation: A UAE study. In C. Gitsaki (Ed.), Teaching and Learning in the Arab World (pp. 377-398). Bern, Switzerland: Peter Lang.

Pascarella, E. T., \& Terenzini, P. T. (1977). Patterns of student-faculty informal interaction beyond the classroom and voluntary freshman attrition. Journal of Higher Education, 48, 540-552.

Pascarella, E. T, \& Terenzini, P. T. (1979). Interaction effects in Spady's and Tinto's conceptual models of college dropout. Sociology of Education, 52, 197-210.

Pascarella, E. T., \& Terenzini, P. T. (1980). Predicting Freshman Persistence and Voluntary Dropout Decisions from a Theoretical Model. The Journal of Higher Education, 51(1), 60-75.

Pearson, E. (2011, August 27). Emirati youth feel the pressure. The National. Retrieved from http://www.thenational.ae/lifestyle/family/emirati-youth-feel-the-pressure

Phelan, P., Davidson, A. L., \& Cao, H. T. (1991). Students' multiple worlds: Negotiating the boundaries of family, peer, and school cultures. Anthropology and Education Quarterly, 22(3), 224-250.

Pillsbury, G., \& Shields, C. M. (1999). Shared journeys and border crossings: When "they" becomes "we." Journal for a Just and Caring Education, 5(4), 410-429.

Pintrich, P. R. (2000). An achievement goal theory perspective on issues in motivation terminology, theory, and research. Contemporary Educational Psychology, 25(1), 92-104.

Porcaro, D. (2011). Applying constructivism in instructivist learning cultures. Multicultural Education \& Technology Journal, 5 (1), 39-54.

Price, L., \& Richardson, J. T. E. (2004). Why is it difficult to improve student learning? In C. Rust (Ed.) Proceedings of the 11th Improving Student Learning Symposium, Improving Student Learning: Theory, Research and Scholarship (pp. 105-120). Oxford: The Oxford Centre for Staff and Learning Development. Retrieved from http://oro.open.ac.uk/11502/

Ridge, N. (2009a). The Search for Solutions: Education Reform in the Gulf. Retrieved from http://www.dsg.ae/En/News/NewsDescription.aspx?NewsID=808

Ridge, N. (2009b). The hidden gender gap in education in the UAE. Dubai School of Government, Policy Brief No.12. Retrieved from http://www.dsg.ae/portals/3/Policy Brief 12 Ridge English.pdf

Ridge, N. (2010). Teacher quality, gender and nationality in the United Arab Emirates: A Crisis for Boys. Dubai School of Government, Working Paper No.10-06. Retrieved from http://www.dsg.ae/en/Publication/Pdf_En/Working Paper 10-06 English.pdf

Ridge, N., \& Farah, S. (2012). The 30\%: who are the males in higher education in the UAE. Policy Paper No.3, Al Qasimi Foundation for Policy Research. Retrieved from http://www.alqasimifoundation.com/Libraries/Publications/Pub4paper_Natasha_Ridge_Samar_Farah.sflb.ashx

Ridge, N., Farah, S., \& Shami, S. (2013). Patterns and perceptions in male secondary school dropouts in the United Arab Emirates. Working Paper No.3, Al Qasimi Foundation for Policy Research. Retrieved from http://www.alqasimifoundation.com/Libraries/Publications/Pub9work_Natasha_Ridge_Samar_Farah_Soha_Shami.sflb.ashx

Salama, S. (2010, April 19). FNC wants laws to preserve Arabic. Gulf News. Retrieved from http://gulfnews.com/news/gulf/uae/general/fnc-wants-laws-to-preserve-arabic-1.614239

Spector, J. M. (2001). An overview of progress and problems in educational technology. Interactive Educational Multimedia, 3, 27-37. 
Swan, M. (2011, September 7). HCT puts lecturers' salary rises on hold. The National. Retrieved from http://www.thenational.ae/news/uae-news/education/hct-puts-lecturers-salary-rises-on-hold

Thornbury, S. (2011). M is for Memorization. Retrieved from http://scottthornbury.wordpress.com/2011/04/08/m-is-for-memorization/

Tinto, V. (1975). Dropout from higher education: a theoretical synthesis of recent research. Review of Educational Research, 45(1), 89-125.

Tinto, V. (1988). Stages of student departure: reflections on the longitudinal character of student leaving. The Journal of Higher Education, 59(4), 438-455.

Tinto, V. (1997). Classrooms as communities: exploring the educational character of student persistence. The Journal of Higher Education, 68(6), 599-623.

Tinto, V. (2006). Research and practice of student retention: what next? Journal of College Student Retention, 8(1), 1-19.

Trompenaars, A., \& Hampden-Turner, C. (1998). Riding the waves of culture: understanding diversity in global business (2nd ed.). New York: McGraw-Hill

UAE population at 8.26m in 2010. (2011). Retrieved from http://www.emirates247.com/news/emirates/uae-population-at-8-26m-in-2010-h1-2011-04-011.375677

UAE Yearbook 2010. (2010). Retrieved from http://www.uaeyearbook.com/yearbook2010.php

VARK. (2011). Retrieved from http://www.vark-learn.com/english/index.asp

Willis, J. W. (2007). Foundations of qualitative research: Interpretive and critical approaches. Thousand Oaks, CA: SAGE.

Willison, J. W. \& Taylor, P. C. (2006). Complementary epistemologies of science teaching towards an integral perspective, metaphor and analogy in science education. Science \& Technology Education Library, 30, 25-36.

World Bank MENA ECD Report. (2009). Retrieved from http://siteresources.worldbank.org/INTMNASUMMNSHD/Resources/IssuesPaper5.12.09FINAL.p $\mathrm{df}$

\footnotetext{
${ }^{1}$ Students could also be accepted for direct entry with CEPA English scores between 180 and 184, dependent upon supporting evidence such as the CEPA Math marks (see Table 1).
} 